\title{
Structural brain injury in sports-related concussion
}

\author{
Scott L. Zuckerman, M.D., ${ }^{1}$ Andrew Kuhn, ${ }^{2}$ Michael C. Dewan, M.D., ${ }^{1}$ \\ Peter J. Morone, M.D., ${ }^{1}$ Jonathan A. Forbes, M.D., ${ }^{1}$ Gary S. Solomon, Ph.D., ${ }^{1}$ \\ and Allen K. Sills, M.D. ${ }^{1}$ \\ ${ }^{1}$ Department of Neurological Surgery, Vanderbilt Sports Concussion Center, Vanderbilt University School of \\ Medicine, Nashville, Tennessee; and ${ }^{2}$ College of Arts and Sciences, Boston University, Boston, Massachusetts
}

\begin{abstract}
Object. Sports-related concussions (SRCs) represent a significant and growing public health concern. The vast majority of SRCs produce mild symptoms that resolve within 1-2 weeks and are not associated with imaging-documented changes. On occasion, however, structural brain injury occurs, and neurosurgical management and intervention is appropriate.

Methods. A literature review was performed to address the epidemiology of SRC with a targeted focus on structural brain injury in the last half decade. MEDLINE and PubMed databases were searched to identify all studies pertaining to structural head injury in sports-related head injuries. studies.

Results. The literature review yielded a variety of case reports, several small series, and no prospective cohort

Conclusions. The authors conclude that reliable incidence and prevalence data related to structural brain injuries in SRC cannot be offered at present. A prospective registry collecting incidence, management, and follow-up data after structural brain injuries in the setting of SRC would be of great benefit to the neurosurgical community. (http://thejns.org/doi/abs/10.3171/2012.10.FOCUS12279)
\end{abstract}

KEY WORDS $\bullet$ concussion $\bullet$ sports $\bullet \quad$ subarachnoid hemorrhage $\bullet$
epidural hemorrhage $\bullet \quad$ subdural hemorrhage $\bullet \quad$ malignant cerebral edema
second-impact syndrome

$\mathrm{C}$ ONCUSSION, also termed mild TBI, is broadly defined as a transient, trauma-induced physiological disruption of brain function. ${ }^{44,79}$ According to the international body of experts making up the Concussion in Sport Group, concussion results in the rapid onset of short-lived impairment of neurological function that resolves spontaneously with no abnormality seen on standard structural neuroimaging studies..$^{59}$ Sports-related concussions comprise nearly $9 \%$ of all injuries sustained during athletics, and emergency department visits for SRCs among children and adolescents have increased by $60 \%$ in the last decade. ${ }^{32,36}$ About one-third of SRCs are sustained by high school football players alone. ${ }^{36}$ While collision and contact sports like football, ice hockey, soccer, and lacrosse garner much attention, concussion rates in other sports are significant. A recent nationwide

\footnotetext{
Abbreviations used in this paper: $\mathrm{AC}=$ arachnoid cyst; ASDH $=$ acute subdural hemorrhage; $\mathrm{CSDH}=$ chronic $\mathrm{SDH} ; \mathrm{EDH}=$ epidural hemorrhage; GCS = Glasgow Coma Scale; LOC $=$ loss of consciousness; MLS = midline shift; $\mathrm{SAH}=$ subarachnoid hemorrhage; $\mathrm{SCI}=$ spinal cord injury; $\mathrm{SIS}=$ second-impact syndrome; SRC $=$ sports-related concussion; SRCSBI $=$ SRC with structural brain injury; $\mathrm{TBI}=$ traumatic brain injury; $\mathrm{SAH}=$ traumatic $\mathrm{SAH}$.
}

study identified girls' soccer, girls' basketball, and boys' wrestling as the second, third, and fourth most implicated sports, respectively, in concussion incidence. ${ }^{54}$ Female athletes seem to be at greater risk for concussion than their sport-matched male counterparts. ${ }^{48,54}$ Similarly, younger athletes appear to not only be more susceptible to concussion, but also take longer to recover. ${ }^{38,105}$

While most concussions produce symptoms that resolve spontaneously, more severe injuries, reflected by positive imaging studies, are seen in a small subset of athletes with SRC. The spectrum of sports-related concussion with structural brain injury (SRCSBI) includes the following: 1) SAH; 2) EDH; 3) SDH; and 4) malignant cerebral edema, dubbed second-impact syndrome, or SIS..$^{10,14,15,57,58,64,101}$ All cases are medical emergencies.

Due to their infrequency, epidemiological and longterm data are lacking for the more severe SRCSBI cases. The objective of our article is to review the literature on sports-related structural head injuries and to offer perspective on how to learn more about these rare injuries and improve treatment, outcomes, and prevention. We also include comments about our own institutional experience with SRCSBI, which has not been previously published. 


\section{Methods}

MEDLINE and PubMed records were searched to identify all studies pertaining to structural injuries in the setting of SRC in the last half-decade. The proceeding terms were used as Medical Subject Heading terms and text words: sport-related head injury, concussion, catastrophic head injury, diffuse axonal injury, epidural hemorrhage, subarachnoid hemorrhage, subdural hemorrhage, malignant cerebral edema, and second impact syndrome. The reference lists of these articles were examined to identify additional relevant research. Of note, we defined "sport-related" as any endeavor in which an individual was performing an athletic activity alone or in competition against an opposing person or team. Traditional team sports were included, such as basketball, football, and soccer, in addition to individual sports such as snowboarding or equestrian events.

\section{Results}

We found a total of 40 articles containing reports of SRCSBI. The study types included 28 case reports, 10 case series, 1 observational cohort design, and 1 casecontrol study. We provide a summary of all sports implicated in reported cases of SRCSBI (Table 1). We present these data based on the type of structural damage seen. When overlap between intracranial injuries existed in a single publication, the paper was categorized based on the most relevant lesion discussed.

\section{Subarachnoid Hemorrhage}

Subarachnoid hemorrhage is defined as bleeding into the subarachnoid space, between the arachnoid membrane and pia mater surrounding the brain. Subarachnoid

TABLE 1: Sports implicated in cases of sport-related structural brain injuries hemorrhage in SRCSBI may be divided into categories based on the site or origin and pattern of bleeding. Isolated tSAH is an uncommon sport-related head injury; the literature is limited to small series and case reports (Table 2). ${ }^{33,77}$ This form of SAH is a consequence of momentary oscillation of the brain as a result of rotational acceleration of the head and subsequent shearing of small cortical vessels..$^{28}$ Often diagnosed on CT scans as a hyperdense focus along the convexity, this type of brain injury has been described as an isolated finding in mild TBI or as a component of additional injuries that includes traumatic axonal injury, SDH, or other structural injuries. ${ }^{29,80}$

Other forms of SAH in athletes may be due to trauma-induced large-vessel damage or aneurysm rupture precipitated by a traumatic event. Blows to the neck or base of the skull caused by a puck (hockey) ${ }^{80}$ collision with a tackler (rugby), ${ }^{61}$ and an opponent's foot (martial arts, kickboxing ${ }^{21,53}$ have all been described as causing vertebral artery injury and subsequent hemorrhage. Subarachnoid hemorrhage caused by aneurysm rupture in the setting of athletic play has also been described in soccer, ${ }^{11}$ hockey, ${ }^{81}$ and weightlifting ${ }^{39}$ sometimes blurring the distinction between tSAH and traditional aneurysmal SAH. In these scenarios, an underlying vascular lesion is subjected to extreme external or hemodynamic forces, precipitating catastrophic hemorrhage.

As in non-sport-related trauma, the finding of a culprit aneurysm portends a worse prognosis, whereas tSAH from cortical vessel rupture alone often involves a benign recovery. In patients with mild TBI, Deepika and associates $^{26}$ demonstrated no difference in outcome between patients with isolated SAH and those with a normal CT scan. In patients with severe TBI, however, there is debate about the risk of tSAH-related cerebral vasospasm and whether antivasospastic therapy should be employed. In a retrospective review of 117 patients with $\mathrm{tSAH}$, Lin et $\mathrm{al}^{47}$ found extensive tSAH to be an independent risk factor for vasospasm, as were age and initial GCS score. Conversely, a study by Shahlaie and coauthors ${ }^{88}$ found only parenchymal contusions and fever-not the presence of SAH-to be associated with posttraumatic vasospasm.

In our clinical practice, SAH is rarely seen after sport-induced mild TBI. In patients with convexity tSAH associated with mild TBI-sports related or otherwiseand reassuring examination findings, antiplatelet or anticoagulation medication is withheld for 1 week, at which point a repeat CT scan is obtained to confirm the evolution and nonexpansion of subarachnoid blood. Furthermore, episodes of tSAH may occur undetected after SRC even in cases of transient concussive symptoms. A high index of suspicion is essential in these situations.

Overall, the literature on sport-related SAH is limited to case report and case series data only. Several reports have cited aneurysm rupture incited by sport-related trauma, whereas others have noted tSAH with no associated aneurysmal involvement. ${ }^{11,83,40}$ The general neurosurgery literature is helpful in extrapolating trends and outcomes, but sport-specific data are lacking.

\section{Epidural Hemorrhage}

An EDH occurs when there is bleeding between the 


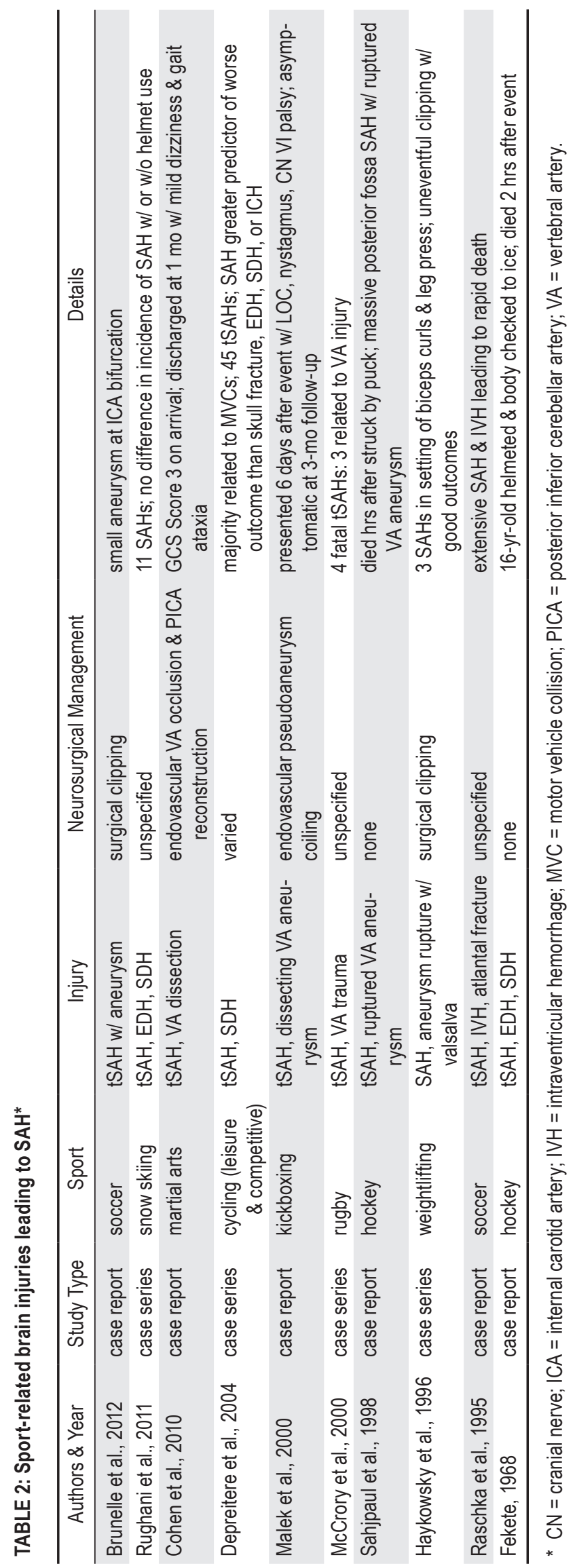

skull and the dura mater. Classically, these intracranial lesions occur secondary to calvarial fractures within the temporal or temporoparietal bone region. ${ }^{8}$ Extradural bleeding most commonly results from tearing of the middle meningeal artery but may be caused by laceration of the middle meningeal vein, diplopic veins, or venous sinuses. ${ }^{13,62}$ Clinical presentation of EDH is varied as patients can present during the so-called lucid interval after a brief period of unconsciousness or arrive comatose upon admission. Neurological deficits can range from minimal to severe with cranial nerve palsies and signs of intracranial herniation.

The most common causes of EDH are traffic-related accidents (53\%), falls (30\%), and assaults (8\%); however, $\mathrm{EDH}$ has also been described as a result of sports-related injuries including golf, skiing, basketball, soccer, and skateboarding (Table 3). ${ }^{12,25,67}$ Rughani et al. ${ }^{80}$ reported finding EDHs, often occurring in unhelmeted athletes, in 3 pediatric skiers, all in the acute setting. Bruzzone and colleagues ${ }^{12}$ reported a delayed EDH in a 19 -year-old soccer player, in whom there was radiographic evidence of an EDH first at 8 hours posttrauma, with negative imaging 80 minutes after the collision. Wang et al. ${ }^{99}$ performed a retrospective analysis of children who had been struck in the head with a golf club while watching another person swing. They found that all patients sustained depressed skull fractures, with 6 of 13 resulting in acute EDH. In these children, all 6 required craniotomy and clot evacuation. Only 1 child experienced long-term neurological sequelae. Overall, the epidemiology and prognosis of patients developing EDH secondary to sports-related injuries has not been well studied.

With respect to sport-related EDH, the current case studies in the literature offer little insight into trends and outcomes. There are as many data on injured sports observers (for example, golfing victims) as there are on athletes. As seen in the next section, SDH is the more common injury in SRCSBI. Although there is likely significant overlap between both injuries, information specific to EDH is difficult to ascertain.

\section{Subdural Hemorrhage}

Subdural hemorrhage, defined as the presence of blood between the outermost dura and arachnoid layer covering the brain, is the most common cause of death due to catastrophic sport-related head injury (http://www. unc.edu/depts/nccsi/). ${ }^{16}$ Often resulting from tearing of bridging veins as they cross the subdural space, SDH can cause a rapid increase in intracranial pressure and subsequent neurological deficit or death. In contrast to EDH, in which secondary injury is often the culprit, the magnitude of impact in SDH damage is greater, leading to significant parenchymal injury, as well as compression with MLS. ${ }^{3,769}$ Both ASDH and CSDH are often diagnosed after a noncontrast head CT scan is acquired. With ASDH, a crescent-shaped mass of hyperdensity is seen along a convexity or the tentorium. Chronic SDH is diagnosed by depiction of a hypodensity along the cerebral convexity, designating chronic blood.

As first reported in the early 20th century, 18 players died during the 1905 college football season, nearly all 


\section{S. L. Zuckerman et al.}

TABLE 3: Sport-related brain injuries leading to EDH*

\begin{tabular}{|c|c|c|c|c|c|}
\hline Authors \& Year & Study Type & Sport & Injury & Neurosurgical Management & Details \\
\hline Wang et al.,2011 & $\begin{array}{l}\text { case series } \\
\qquad(n=13)\end{array}$ & golf & acute temporal EDH & craniotomy & $\begin{array}{l}\text { only } 1 \text { patient had long-term neurological } \\
\text { sequelae after EDH evacuation }\end{array}$ \\
\hline Nemecek et al., 2005 & case report & $\begin{array}{l}\text { skateboard- } \\
\text { ing }\end{array}$ & delayed vertex EDH & no surgical intervention & $\begin{array}{l}\text { EDH located overlying the SSS; no op inter- } \\
\text { vention due to increased risk to sinus tear } \\
\text { during EDH evacuation; patient now w/o } \\
\text { neurological deficits }\end{array}$ \\
\hline Bruzzone et al., 2000 & case report & soccer & $\begin{array}{l}\text { acute frontoparietal } \\
\text { EDH }\end{array}$ & craniotomy & $\begin{array}{l}\text { 9-mo follow-up w/ no seizures \& neurophysi- } \\
\text { ological testing w/in normal range }\end{array}$ \\
\hline Datti et al., 1995 & case report & basketball & acute temporal EDH & craniotomy & $\begin{array}{l}\text { patient discharged w/o neurological deficits; } \\
\text { basketball has a low risk of nervous sys- } \\
\text { tem injuries }\end{array}$ \\
\hline
\end{tabular}

* SSS = superior sagittal sinus.

due to SDH.16 The more popular sports, such as football, soccer, and hockey, have been implicated in SDH, as have lesser practiced athletic endeavors, such as snowboarding, martial arts, and race walking. ${ }^{17,35,76,95,96}$ The majority of SDHs are acute, and immediate hospitalization and neurosurgical treatment are indicated; however, $\mathrm{CSDHs}$ have been reported. A 43-year-old man suffered a CSDH due to a basketball injury, returning to the hospital weeks later with debilitating headaches. ${ }^{43}$ A 65 -year-old man receiving warfarin presented with left leg weakness and headache, and imaging showed a chronic SDH; the authors reported the bleed was likely due to the jarring impact of race walking. ${ }^{17}$

The literature on SDH due to sport-related head injury includes the highest level of evidence, a case-control study, rather than single reports or small series (Table 4). ${ }^{52,55,74,94}$ Kushi and associates ${ }^{46}$ compared 10 boxers with ASDH compared with 26 nonboxers with ASDH. They found that boxing-related ASDHs occurred in younger patients who experienced lucid intervals, without cerebral contusions. No between-group differences were noted for GCS score, MLS, or overall prognosis. ${ }^{46}$

Within the existing case reports, an interesting theme emerged in that several athletes reported a recent head injury prior to the inciting impact leading to $\mathrm{SDH} .{ }^{45,49,51}$ Not to be confused with diffuse cerebral edema or SIS, in which the brain loses its ability to autoregulate and massively swells, malignant edema is not seen in these cases. Kersey ${ }^{45}$ reported on a 19 -year-old football player with acute ASDH 35 days after sustaining a mild concussion. The patient underwent a craniotomy and recovered without neurological deficit, despite presenting with decerebrate posturing and a fixed and dilated left pupil. The second impact, involving a presumptive minor head injury immediately prior to SDH, could not be recalled by the player or by spectators. Logan et al. ${ }^{51}$ similarly described 2 unreported episodes of head trauma preceding an ASDH in an 18-year-old football player who underwent medical management. The specific head injury precipitating the ASDH could not be identified, yet the athlete recalled 2 prior unreported head impacts that caused symptoms of headache and nausea. In 1995, $\mathrm{Litt}^{49}$ reported on a 16-year-old football player with concussion and symptom resolution 16 days postinjury. The athlete was cleared to play 30 days after the initial concussion. During his first game back, the player collided with an opposing player, was taken out of the game, and quickly experienced deterioration on the sideline. Attending neurosurgeons at a local emergency department diagnosed ASDH, and a bur hole craniotomy was performed. Lastly, in their critical review of sudden death in young, competitive athletes, Thomas et al. ${ }^{93}$ found that $17 \%$ of the 138 football players who died of head/neck trauma had a history of concussion several days to 4 weeks prior to injury.

This theme is echoed in our own institutional experience. In the last 3 years, 2 high school football players presented to our pediatric emergency department with ASDH, one 15-year-old managed medically and one 17-year-old requiring craniotomy. Both players and coaches reported head trauma within the 2 weeks preceding their presentation to medical attention. Neither player was diagnosed with a concussion during the game where the original injury was thought to have occurred. Of note, both players' helmets were tested under standard National Operating Committee for the Safety of Athletic Equipment guidelines. ${ }^{66}$ Both helmets passed the aforementioned guidelines, deeming them adequate to protect against the accepted minimum levels of linear acceleration.

A second theme among the SDH case reports links arachnoid cysts to an increased risk of sport-related $\mathrm{CSDH}^{75}$ Arachnoid cysts occur in $1 \%$ of the population and can be complicated by intracystic, subdural, or epidural bleeding caused by damage to surrounding veins. ${ }^{19,34,40,75,98,100}$ The annual risk of cyst hemorrhage has been reported to be less than $0.1 \% .^{71,87}$ Treatment for problematic arachnoid cysts includes fenestration of the cyst with or without excision, or shunting the cyst contents to the peritoneal cavity.11

Prabhu and Bailes. ${ }^{75}$ reported the case of a 16-yearold girl who was struck in the head by a soccer ball and presented 1 month later with headaches and numbness on the right side of her face. She was found to have a large, chronic and subacute SDH and underwent craniotomy and cyst fenestration. Zeng et al. ${ }^{103}$ reported 2 similar cases. In the first, a 14-year-old boy suffered a residual headache of several weeks' duration after vigorous jumping during 


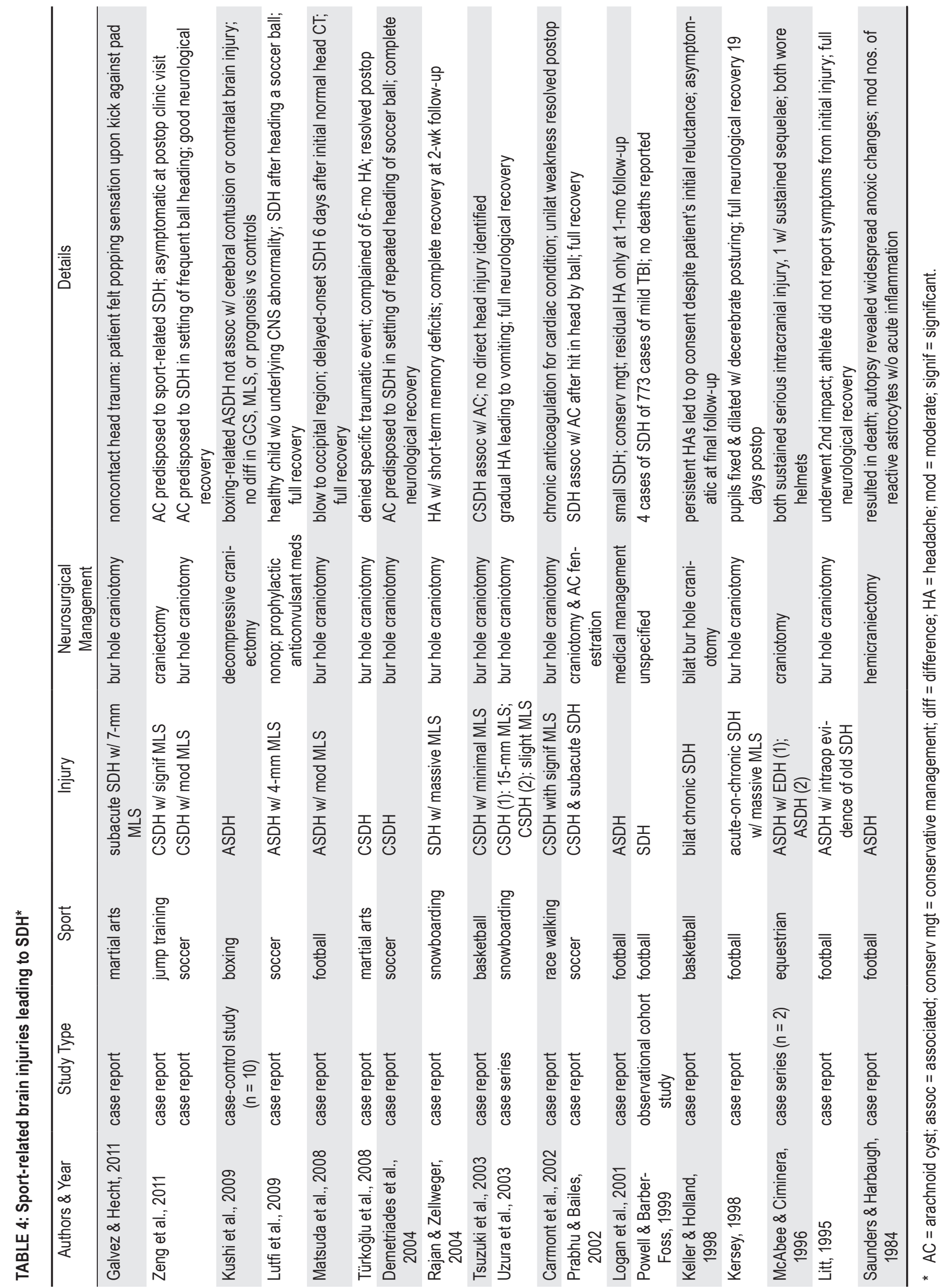




\section{S. L. Zuckerman et al.}

youth sport activities. He was then seen in an outpatient primary care setting and found to have an arachnoid cyst. Several weeks later, the patient presented with worsening headache and projectile vomiting, and he was found to have intracystic bleeding and a left-side CSDH with significant shift. A craniectomy was performed to evacuate the CSDH, and the cyst was fenestrated. In the second case, a 16-year-old male soccer player had a 4-week history of headache and nausea. He denied history of trauma other than frequent heading of the soccer ball. Magnetic resonance imaging showed $\mathrm{CSDH}$ and left middle fossa arachnoid cyst despite the absence of neurological deficit. A bur hole craniotomy was performed, and the CSDH was evacuated. Similarly, Demetriades et al. ${ }^{27}$ reported the case of a 24-year-old soccer player with a 6-week history of headache and nausea and no history of head trauma except for regular heading during soccer practice. The patient was found to have a CSDH overlying a portion of arachnoid cyst and underwent craniotomy.

The earliest link between arachnoid cysts and CSDH was noted in $1971 .{ }^{104}$ Chronic SDH complicates approximately $20 \%$ of arachnoid cysts. One theory states that because arachnoid cysts are less compliant than normal brain tissue, less cushioning is provided during minor trauma, increasing the likelihood of bridging vein rupture. ${ }^{103}$ Bilginer et al. ${ }^{5}$ studied 132 patients with arachnoid cysts and found that the risk of associated SDH was $2.27 \%$ (3 cases). Mori and colleagues ${ }^{63}$ reported this rate to be $1.5 \%$ in 541 patients. The risk of arachnoid cyst hemorrhage with SDH secondary to a sports-related head trauma is unknown; however reports have been published on boxing, basketball, racing, jumping, and football. ${ }^{27,75,103}$ Given the anecdotal increased risk of SDH in young patients with arachnoid cysts, screening may be indicated for those involved in sports who have sustained repetitive head trauma. Only in extreme cases may it be prudent for a careful risk-benefit discussion between the surgeon and the family of certain athletes concerning surgical removal. There have been no reports of prophylactic surgery for arachnoid cysts in the setting of competitive sports.

Overall, SDH is the first structural injury to offer a case-control study and themes within the case reports. There is a propensity for SDH after a minor head trauma, oftentimes associated with multiple subconcussive impacts. Furthermore, an arachnoid cyst may increase a young athlete's risk for acute or chronic SDH.

\section{Diffuse Cerebral Edema}

As he first described in his 1973 book, Head and Neck Injuries in Football: Mechanisms, Treatment, and Prevention, neurosurgeon Richard Schneider reported an initial concussion in 2 young athletes who subsequently died after a second, minor head injury that produced diffuse cerebral edema. ${ }^{85,101}$ The term "second-impact syndrome," or SIS, was coined 11 years later by Saunders and Harbaugh, ${ }^{83}$ in their description of a 19-year-old college football player who collapsed and died on the field 4 days after a concussion. Today, SIS is defined as occurring when "[a]n athlete who has sustained an initial head injury, most often a concussion, sustains a second head injury before symptoms associated with the first have fully cleared" and when the second, minor injury, perhaps only involving a blow to the torso, results in catastrophic brain swelling and death. ${ }^{14,42,60,83,91}$ Second-impact syndrome occurs primarily in male adolescents and/or teenagers, rarely in females, most often during football, but has been seen in boxing, martial arts, and skiing. 15,58,64 The pathophysiology of SIS involves a rapid loss of autoregulation, combined with a catecholamine surge, leading to a paralyzed arterial tree unable to respond to rapid escalation of blood pressure. 9,10,42,50,89,91,101 Furthermore, a key finding in SIS is absence of an expanding intracranial hematoma causing compression. A thin, acute SDH may be seen, but without mass effect; rapid, malignant cerebral edema is the major culprit in SIS. ${ }^{15,64}$

Since its initial description, the existence of SIS has been marred with controversy. Several experts support the underlying pathophysiology, ${ }^{14,15}$ whereas another contingent has argued against its existence, positing that it is simply a higher-magnitude SDH with edema and poorer outcome. ${ }^{57,58}$ The epidemiology of SIS is largely based on anecdotal case reports, complicated by the debate over whether SIS exists (Table 5). ${ }^{73,101}$ McCrory ${ }^{57}$ believes that by the strict definition of SIS, only 5 cases meet criteria for "probable SIS," with several reports being excluded. The US National Center for Catastrophic Sport Injury Research cited 145 cases of catastrophic cerebral injury over a 26-year period with only a single case of possible SIS (http://www.unc.edu/depts/nccsi/). However, Cantu and Gean ${ }^{15}$ recently reported 10 cases of SIS associated with a slim, acute SDH. They maintained that the inciting acceleration forces required to produce a small SDH reach the threshold to produce SIS in the setting of previously damaged brain tissue. Mori et al. ${ }^{64}$ reported a similar case series of 18 patients, but they hypothesized that the "more impressive" brain swelling was likely due to the thin SDH.

A debate over the existence of SIS is beyond the scope of this article. However, it is inarguable that malignant brain swelling with catastrophic outcome has been documented and that reliable epidemiological data are needed to correctly manage minor concussive sport-related head injury. The fear of SIS continues to drive return-to-play guidelines and concussion safety protocols. ${ }^{58}$ Albeit SIS is rare, knowing its true risk is crucial for neurosurgeons and providers to establish reliable safety parameters. Dutiful reporting of diffuse cerebral edema cases is needed.

\section{Discussion}

Concussion is a common sports injury, seen at the youth, high school, college, and professional level. An army of health care providers is involved in the treatment of individuals with these mild brain injuries, including certified athletic trainers, internists, pediatricians, family practitioners, neuropsychologists, neurologists, and neurosurgeons. With proper knowledge of concussive injury and management and an evidence-based approach to return to play, many health care providers can successfully manage SRCs. However, only one population possesses the training to treat structural brain injuries requiring acute surgical intervention. In the setting of these life- 


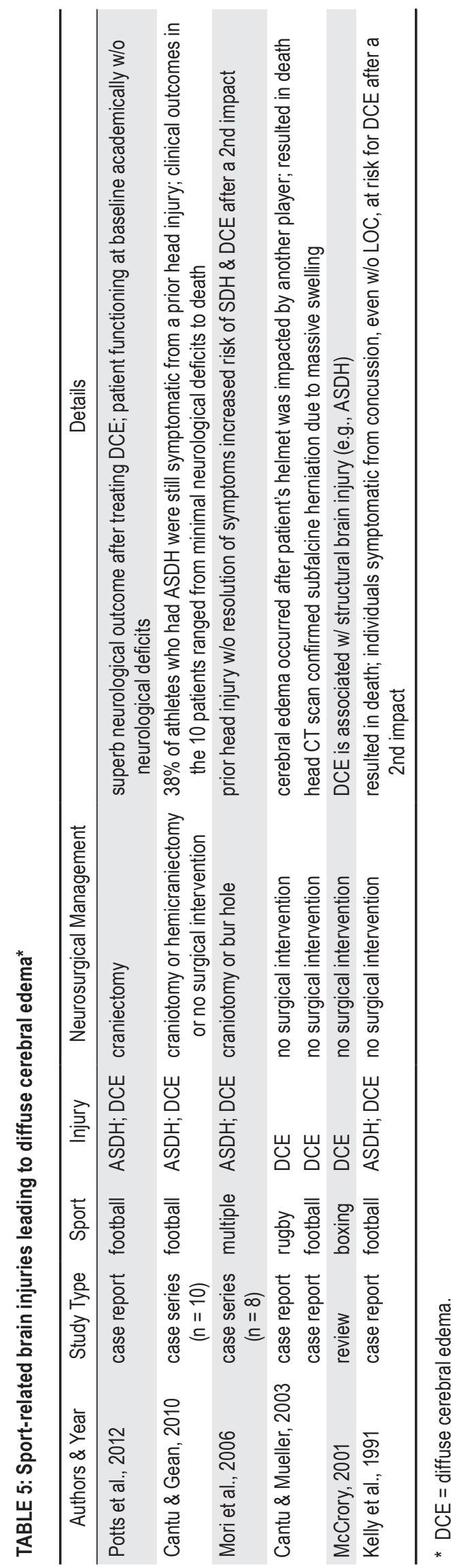

altering injuries, where permanent neurological deficits or death occur $60 \%$ of the time, neurosurgeons are called on to intervene. ${ }^{6}$

Whereas concussions are transient and lack positive neuroimaging findings, severe TBI can lead to permanent neurological deficit and have definitive imaging findings. The international Concussion in Sport Group defines concussion as a "complex pathophysiologic process affecting the brain, induced by traumatic biomechanical forces." 59 Because concussion is typically a functional injury that is often unaccompanied by identifiable structural insults, postconcussion treatment is largely observational, behavioral (for example, rest and the avoidance of noxious environmental stimuli that can exacerbate symptoms), and preventative of secondary injury. Beyond rest and recovery, there have been modest efforts to introduce pharmacological agents into the postconcussion treatment realm. Recent reviews of the role of pharmacology in SRC have been provided by Petraglia and coworkers ${ }^{72}$ and by Solomon and Sills..$^{90}$ A recent retrospective case-control study suggests that the use of amantadine may improve reported symptoms, verbal memory, and reaction time in patients suffering from a recent SRC. ${ }^{78}$

Our review demonstrates the paucity of current data and suggests that much work remains to be done. In the subsequent sections we explore the potential mechanisms that may be used to better address this problem from a public health perspective. These strategies include the use of a national registry, continued emphasis on education and prevention programs, and changes in public policy.

\section{National Registries}

A patient registry is defined as "an organized system that uses observational study methods to collect uniform data to evaluate specified outcomes for a population defined by a particular disease, condition or exposure, which serves predetermined scientific, clinical or policy purpose(s)." 37 With strong methodology and systematic research questioning, registries can provide longitudinal patient outcome data, improving our knowledge of specific health states and allowing critical evaluation of interventions. ${ }^{37,70}$ Key points to consider when designing a registry include formulating a question, choosing a study design, translating question of clinical interest into measurable outcomes, choosing patients, and deciding how many patients need to be studied for how long. ${ }^{37}$ An indepth discussion of registry science is outside the scope of this article, but rich literature exists describing the design and implementation of patient registries. ${ }^{37}$

In the realm of SRCSBI registries, the National Center for Catastrophic Sports Injury Research has served as the leader in recording these rare injuries. Since 1965, it has collected valuable information on demographic patterns, mechanism, and injury timing, with the most recent 2011 Survey of Catastrophic Football Injuries highlighting the summary data. ${ }^{65}$ However, its focus remains on epidemiological data, rather than prospective, outcomesbased registry information. Treatment and long-term follow-up data are outside the scope of the efforts of the National Center for Catastrophic Sports Injury Research. Outside of sports, several robust patient registries 


\section{S. L. Zuckerman et al.}

exist collecting TBI and SCI data. Researchers in Korea established the Korean Brain Rehabilitation Registry for patients with stroke, TBI, brain tumors, and other brain disorders. ${ }^{102}$ Over an approximately 2 -year period, they enrolled 1697 patients and recorded measurable functional improvement outcomes throughout the rehabilitation process. Similarly, in the US, researchers in Philadelphia have established a registry for post-stroke or -TBI patients by recording their cognitive rehabilitation progress for several years after the initial injury. ${ }^{86}$ With respect to SCI registries, the Rick Hansen Spinal Cord Injury Registry was launched in 2004 to improve outcomes in patient with SCIs. ${ }^{70}$ Based in Canada, this registry created a standardized set of clinical information to record outcomes from several international centers. For each patient, 265 data elements are recorded and patients are contacted up to 10 years from the date of injury, with regular 5-year contacts thereafter. In the US, the National Spinal Cord Injury Database has similarly aimed to further our understanding of Spinal Cord Injury and predictors of quality of life. ${ }^{30,42,70}$ Internationally, the European Multicenter Study about Spinal Cord Injury has evaluated SCI injury scales and recovery patterns. ${ }^{24}$ It is imperative to highlight the emphasis these registries place on recovery and outcomes rather than epidemiology alone

The neurosurgical community has invested heavily in registry-based initiatives. Recently, the American Association of Neurological Surgeons created a prospective data collection tool that includes case data from surgeons throughout the country. The National Neurosurgery Quality and Outcomes Database, or $\mathrm{N}^{2} \mathrm{QOD}$, is a national registry that serves to include quality and outcomes data in an effort to define the quality of care delivered. ${ }^{68}$ It is appropriate that the management of SRCSBI be addressed in a similar manner. In this way, decisions regarding the safety of our athletes will no longer be based upon case reports, small series, and anecdotal evidence but, rather, upon a large prospective tool accessible to health care personnel, coaches, and policymakers alike.

\section{Education and Injury Prevention Programs}

Bramley et al. ${ }^{7}$ recently demonstrated that high school soccer players with education training in concussions are more likely to notify their coach of a suspected concussion than players with no such training. Education is crucial in changing the SRCSBI landscape. The existing SRC management education literature serves as a useful model. In response to the public health problem of SRC, several organizations have risen to the occasion.

The Center for Disease Control and Prevention, through the Children's Health Act of 2000, implemented a national concussion education and awareness program. ${ }^{82}$ In 2005, "Heads Up: Concussion in High School Sports," directed toward high school coaches, athletic directors, and certified athletic trainers, was launched. ${ }^{84}$ The tool kit included a guide for coaches and videos, clipboard stickers, wallet cards, and fact sheets for parents and athletes. ${ }^{84}$ Within 3 months, the Center for Disease Control and Prevention distributed over 20,000 tool kits nationwide. The most recent iteration of the tool kit is available at www. cdc.gov/Concussion.
Chrisman et al..$^{20}$ randomly surveyed 414 physicians across the US; 183 received the Heads Up tool kit and 231 served as a controls. Physicians who received the tool kit were significantly less likely to recommend next-day return to play after SRC. Similarly, Sarmiento et al.$^{82}$ administered the Heads Up tool kit to high school coaches and found favorable changes in knowledge, attitudes, and practices toward the prevention and management of concussions. Covassin et al. ${ }^{23}$ distributed the same educational material to 340 youth sport coaches, who were found to be better able to prevent, recognize, and respond to SRC, with nearly three-quarters of coaches now educating others on SRC. Efforts have also been made to reach out to school personnel and special education staff who play an equally important role in identifying the effects of concussive symptoms through the initiative "Heads Up to Schools: Know Your Concussion ABCs." 82

The Sports Legacy Institute Community Educators, or SLICE, curriculum for student athletes seeks to educate student athletes on concussion diagnosis and management. ${ }^{4}$ Its program features medically trained students who deliver interactive presentations to their peer student athletes. Bagley et al. ${ }^{4}$ administered quizzes before and after the SLICE presentation to 636 students ages 9-18 years and found significant improvement in concussion knowledge in all subgroups. Presentations lasted 40-60 minutes and were highly interactive, including PowerPoint slides, videos, audience participation, case studies, and personal testimonials. In Canada, the ThinkFirst program has similarly succeeded in furthering concussion injury prevention by teaching mechanisms, consequences, and prevention of brain injuries in sports, most often to hockey players. ${ }^{18,22}$ The program has also been expanded to kids in kindergarten to 6th grade. ${ }^{97}$

The advent of social media provides another avenue for concussion education. Ahmed et al. ${ }^{2}$ recently analyzed the use of social networking sites for SRC by analyzing Facebook postings. From the 17 Facebook groups studied, the authors found that people most often shared their concussion experience online and also sought or offered advice on concussion management. They pointed out the evolving nature of health education and highlighted the crucial peer-to-peer interaction that takes place. ${ }^{2}$ Sullivan et al..$^{92}$ also sought to determine the context of mild TBI in the online population. The authors identified and classified 3488 concussion-related Tweets and categorized them appropriately, highlighting the powerful potential of Twitter to serve as broadcast medium for sports concussion information and education. At our own institution, we have developed a smartphone application for concussion safety to be used on the sidelines.

Sports-related concussions with structural brain injury are exceedingly rare, which makes education a challenge. Similar modules and tool kits would serve to increase awareness of these devastating injuries, but the condition presents a greater challenge than SRC management. Sports-related concussions are ubiquitous-virtually every coach has witnessed a player suffer an SRC, and every athlete has a teammate who has sustained a concussion. With SRCSBI, however, coaches, parents, school personnel, and players may be less enthusiastic 
about learning because of the injury's rarity. Organized efforts to educate and alert the sports community about the devastating and potentially irreversible consequences of failure to identify these injuries can ameliorate the educational gap.

\section{Policy Changes}

Effective concussion prevention requires legislation in addition to education. ${ }^{1}$ The prototype model of a "concussion law" has been the Zackery Lystedt Law, passed in Washington State in 2006. In 2003, Zack was playing in a high school football game and suffered a concussion. He returned to play in that same game. Several plays later, he received another blow to the head that caused life-threatening bilateral SDH, leading to permanent neurological deficits and necessitating the use of a wheelchair. The new legislation proposed prompted by his injury contained several key provisions: 1) informed consent must be given in writing by parents of youth athletes prior to the first practice; 2) any athlete with a suspected concussion must be taken out of the game; and 3) a player cannot return to play until cleared by a licensed health care provider trained in concussion management. ${ }^{1,31}$

Since the enactment of the Lystedt law in 2009, national organizations, including the American College of Sports Medicine and the National Football League, have joined forces to promote legislation regarding concussion education, prevention, and management. Over 40 states have either laws or bills pending that address concussion in youth sports. ${ }^{4}$

Extending legislation to SRCSBI should also be considered. Sports-related concussion laws will certainly help prevent devastating structural brain injuries, but additional legislation specific to SRCSBI may be needed. In our opinion, this begins with mandatory notification to a national injury registry. Armed with these data, patterns of injury can be tracked over time and the benefits of any such future sports-related legislation can be objectively measured. Other examples of possible legislation include debriefing with players and coaches after a catastrophic injury occurs, assessment of equipment involved in injury, and harsh penalties to coaches and/or schools who do not adhere to appropriate return-to-play policies. While coaches are generally expected to act in the best interest of the player, there is often a direct conflict of interest when weighing the decision to withhold a player from the field in the heat of a competitive game. The consequences for such decisions are amplified in SRCSBI, which may initially be perceived as an uncomplicated concussion.

\section{Conclusions}

Our review of the literature demonstrates the essential absence of prospective studies assessing the epidemiology and outcome of structural injury in SRC. The current structural injury literature is composed of small series, case reports, and one case-control study. Given the infrequency of these specific injuries, the state of the literature, although appreciated, is understood as limited. We conclude that reliable incidence and prevalence data related to SRCSBI cannot be offered at present.
Thus, we propose that the field of neurosurgery address this gap in the knowledge base of structural injury in SRC. As athletes at all levels become stronger and faster, and with the size of playing fields unchanged, physics and biomechanics would suggest that neurosurgeons may be seeing more cases of SRCSBI in the future. With respect to football, there are approximately 2000 professional players, 75,000 college players, and 1.2 million high school players, with an additional 250,000 competing at the Pop Warner level (http://www.popwar ner.com/football.htm). ${ }^{6}$ Although the professional level receives ubiquitous media attention and financial support, specifically the formation of the National Football League Head, Neck, and Spine Committee (http://www. nflevolution.com), the scope of this problem is most critical at the youth level. With decreased funding for equipment refurbishment and adequately trained sports medicine clinicians on the sidelines, many sports injuries may go unnoticed and/or unreported.

It is incumbent on the field of neurosurgery to provide comprehensive information in an effort to offer empirical epidemiological, risk, and follow-up data. Such information should include the incidence of structural injury, type of structural injury, whether the injury was managed medically or surgically, possible risk factors for the structural injury (for example, arachnoid cyst, multiple concussions, and so on), and several years of followup. Given the current climate of media focus, and the need to intervene in this public health problem, it would seem beneficial that neurosurgeons participate in reporting these cases, furthering SRCSBI education and helping to pass appropriate legislation.

\section{Disclosure}

The authors report no conflict of interest concerning the materials or methods used in this study or the findings specified in this paper.

Author contributions to the study and manuscript preparation include the following. Conception and design: Zuckerman, Solomon, Sills. Acquisition of data: Zuckerman, Kuhn, Dewan, Morone. Analysis and interpretation of data: Zuckerman, Dewan, Morone. Drafting the article: Zuckerman, Kuhn, Dewan, Morone, Forbes, Solomon. Critically revising the article: Zuckerman, Dewan, Morone, Forbes, Solomon, Sills. Reviewed submitted version of manuscript: Zuckerman, Forbes, Solomon, Sills. Approved the final version of the manuscript on behalf of all authors: Zuckerman. Administrative/technical/material support: Solomon, Sills. Study supervision: Solomon, Sills.

\section{References}

1. Adler RH, Herring SA: Changing the culture of concussion: education meets legislation. PM R 3 (10 Suppl 2):S468-S470, 2011

2. Ahmed OH, Sullivan SJ, Schneiders AG, McCrory P: iSupport: do social networking sites have a role to play in concussion awareness? Disabil Rehabil 32:1877-1883, 2010

3. Aoki N, Oikawa A, Sakai T: Symptomatic subacute subdural hematoma associated with cerebral hemispheric swelling and ischemia. Neurol Res 18:145-149, 1996

4. Bagley AF, Daneshvar DH, Schanker BD, Zurakowski D, D'hemecourt CA, Nowinski CJ, et al: Effectiveness of the SLICE Program for youth concussion education. Clin J Sport Med 22:385-389, 2012 


\section{S. L. Zuckerman et al.}

5. Bilginer B, Onal MB, Oguz KK, Akalan N: Arachnoid cyst associated with subdural hematoma: report of three cases and review of the literature. Childs Nerv Syst 25:119-124, 2009

6. Boden BP, Tacchetti RL, Cantu RC, Knowles SB, Mueller FO: Catastrophic head injuries in high school and college football players. Am J Sports Med 35:1075-1081, 2007

7. Bramley H, Patrick K, Lehman E, Silvis M: High school soccer players with concussion education are more likely to notify their coach of a suspected concussion. Clin Pediatr (Phila) 51:332-336, 2012

8. Bricolo AP, Pasut LM: Extradural hematoma: toward zero mortality. A prospective study. Neurosurgery 14:8-12, 1984

9. Bruce DA: Delayed deterioration of consciousness after trivial head injury in childhood. Br Med J (Clin Res Ed) 289:715716,1984

10. Bruce DA, Alavi A, Bilaniuk L, Dolinskas C, Obrist W, Uzzell B: Diffuse cerebral swelling following head injuries in children: the syndrome of "malignant brain edema." J Neurosurg 54: 170-178, 1981

11. Brunelle C, Hennecker JL, Scordidis V: [Loss of consciousness after a minor trauma revealing an aneurysm rupture in a child.] Arch Pediatr 19:815-818, 2012 (Fr)

12. Bruzzone E, Cocito L, Pisani R: Intracranial delayed epidural hematoma in a soccer player. A case report. Am J Sports Med 28:901-903, 2000

13. Bullock MR, Chesnut R, Ghajar J, Gordon D, Hartl R, Newell DW, et al: Surgical management of acute epidural hematomas. Neurosurgery 58 (3 Suppl):S16-S24, 2006

14. Cantu RC: Second-impact syndrome. Clin Sports Med 17: 37-44, 1998

15. Cantu RC, Gean AD: Second-impact syndrome and a small subdural hematoma: an uncommon catastrophic result of repetitive head injury with a characteristic imaging appearance. J Neurotrauma 27:1557-1564, 2010

16. Cantu RC, Mueller FO: Brain injury-related fatalities in American football, 1945-1999. Neurosurgery 52:846-853, 2003

17. Carmont MR, Mahattanakul W, Pigott T: Acquisition of a chronic subdural haematoma during training for competitive race walking? Br J Sports Med 36:306-307, 2002

18. Carson J, Tator C, Johnston K, Kissick J, Purcell L, Hunt B: New guidelines for concussion management. Can Fam Physician 52:756-757, 2006

19. Choi JU, Kim DS: Pathogenesis of arachnoid cyst: congenital or traumatic? Pediatr Neurosurg 29:260-266, 1998

20. Chrisman SP, Schiff MA, Rivara FP: Physician concussion knowledge and the effect of mailing the CDC's "Heads Up" toolkit. Clin Pediatr (Phila) 50:1031-1039, 2011

21. Cohen JE, Margolin E, Moscovici S, Paldor I, Itshayek E: Life-threatening massive subarachnoid hemorrhage after Taekwondo-associated head trauma. Isr Med Assoc J 12:509510,2010

22. Cook DJ, Cusimano MD, Tator CH, Chipman ML: Evaluation of the ThinkFirst Canada, Smart Hockey, brain and spinal cord injury prevention video. Inj Prev 9:361-366, 2003

23. Covassin T, Elbin RJ, Sarmiento K: Educating coaches about concussion in sports: evaluation of the CDC's "Heads Up: concussion in youth sports" initiative. J Sch Health 82:233238,2012

24. Curt A, Van Hedel HJ, Klaus D, Dietz V: Recovery from a spinal cord injury: significance of compensation, neural plasticity, and repair. J Neurotrauma 25:677-685, 2008

25. Datti R, Gentile SL, Pisani R: Acute intracranial epidural haematoma in a basketball player: a case report. Br J Sports Med 29:95-96, 1995

26. Deepika A, Munivenkatappa A, Devi BI, Shukla D: Does isolated traumatic subarachnoid hemorrhage affect outcome in patients with mild traumatic brain injury? J Head Trauma Rehabil [epub ahead of print], 2012

27. Demetriades AK, McEvoy AW, Kitchen ND: Subdural haema- toma associated with an arachnoid cyst after repetitive minor heading injury in ball games. Br J Sports Med 38:E8, 2004

28. Demirçivi F, Ozkan N, Büyükkeçeci S, Yurt I, Miniksar F, Tektaş S: Traumatic subarachnoid haemorrhage: analysis of 89 cases. Acta Neurochir (Wien) 122:45-48, 1993

29. Depreitere B, Van Lierde C, Maene S, Plets C, Vander Sloten J, Van Audekercke R, et al: Bicycle-related head injury: a study of 86 cases. Accid Anal Prev 36:561-567, 2004

30. Dijkers MP: Correlates of life satisfaction among persons with spinal cord injury. Arch Phys Med Rehabil 80:867-876, 1999

31. Ellenbogen RG, Berger MS, Batjer HH: The National Football League and concussion: leading a culture change in contact sports. World Neurosurg 74:560-565, 2010

32. Faul M, Xu L, Wald MM, Coronado VG: Traumatic Brain Injury in the United States: Emergency Department Visits, Hospitalizations, and Deaths 2002-2006. Atlanta: Centers for Disease Control and Prevention, National Center for Injury Prevention and Control, 2010 (http://www.cdc.gov/ traumaticbraininjury/pdf/blue_book.pdf) [Accessed October 15, 2012]

33. Fekete JF: Severe brain injury and death following minor hockey accidents: the effectiveness of the "safety helmets" of amateur hockey players. Can Med Assoc J 99:1234-1239, 1968

34. Fewel ME, Levy ML, McComb JG: Surgical treatment of 95 children with 102 intracranial arachnoid cysts. Pediatr Neurosurg 25:165-173, 1996

35. Galvez JC, Hecht S: Subacute subdural hematoma in a Karate instructor after noncontact head trauma. Curr Sports Med Rep 10:11-13, 2011

36. Gessel LM, Fields SK, Collins CL, Dick RW, Comstock RD: Concussions among United States high school and collegiate athletes. J Athl Train 42:495-503, 2007

37. Gliklich RE, Dreyer NA (eds): Registries for Evaluating Patient Outcomes: A User's Guide, ed 2. Rockville, MD: Agency for Healthcare Research and Quality, 2010

38. Guskiewicz KM, Valovich McLeod TC: Pediatric sports-related concussion. PM R 3:353-364, 2011

39. Haykowsky MJ, Findlay JM, Ignaszewski AP: Aneurysmal subarachnoid hemorrhage associated with weight training: three case reports. Clin J Sport Med 6:52-55, 1996

40. Ildan F, Cetinalp E, Bağdatoğlu H, Boyar B, Uzuneyüoglu Z: Arachnoid cyst with traumatic intracystic hemorrhage unassociated with subdural hematoma. Neurosurg Rev 17:229232, 1994

41. Jackson AB, Dijkers M, Devivo MJ, Poczatek RB: A demographic profile of new traumatic spinal cord injuries: change and stability over 30 years. Arch Phys Med Rehabil 85:17401748,2004

42. Jünger EC, Newell DW, Grant GA, Avellino AM, Ghatan S, Douville CM, et al: Cerebral autoregulation following minor head injury. J Neurosurg 86:425-432, 1997

43. Keller TM, Holland MC: Chronic subdural haematoma, an unusual injury from playing basketball. Br J Sports Med 32: 338-339, 1998

44. Kelly JP, Nichols JS, Filley CM, Lillehei KO, Rubinstein D, Kleinschmidt-DeMasters BK: Concussion in sports. Guidelines for the prevention of catastrophic outcome. JAMA 266: 2867-2869, 1991

45. Kersey RD: Acute subdural hematoma after a reported mild concussion: a case report. J Athl Train 33:264-268, 1998

46. Kushi H, Saito T, Sakagami Y, Ohtsuki J, Tanjoh K: Acute subdural hematoma because of boxing. J Trauma 66:298-303, 2009

47. Lin TK, Tsai HC, Hsieh TC: The impact of traumatic subarachnoid hemorrhage on outcome: a study with grouping of traumatic subarachnoid hemorrhage and transcranial Doppler sonography. J Trauma Acute Care Surg 73:131-136, 2012 
48. Lincoln AE, Caswell SV, Almquist JL, Dunn RE, Norris JB, Hinton RY: Trends in concussion incidence in high school sports: a prospective 11-year study. Am J Sports Med 39: 958-963, 2011

49. Litt DW: Acute subdural hematoma in a high school football player. J Athl Train 30:69-71, 1995

50. Lobato RD, Rivas JJ, Gomez PA, Castañeda M, Cañizal JM, Sarabia R, et al: Head-injured patients who talk and deteriorate into coma. Analysis of 211 cases studied with computerized tomography. J Neurosurg 75:256-261, 1991

51. Logan SM, Bell GW, Leonard JC: Acute subdural hematoma in a high school football player after 2 unreported episodes of head trauma: a case report. J Athl Train 36:433-436, 2001

52. Lutfi R, Mullett CJ, Nield LS: Acute subdural hematoma: potential soccer injury in an otherwise healthy child. Pediatr Emerg Care 25:582-583, 2009

53. Malek AM, Halbach VV, Phatouros CC, Meyers PM, Dowd CF, Higashida RT: Endovascular treatment of a ruptured intracranial dissecting vertebral aneurysm in a kickboxer. J Trauma 48:143-145, 2000

54. Marar M, McIlvain NM, Fields SK, Comstock RD: Epidemiology of concussions among United States high school athletes in 20 sports. Am J Sports Med 40:747-755, 2012

55. Matsuda W, Sugimoto K, Sato N, Watanabe T, Fujimoto A, Matsumura A: Delayed onset of posttraumatic acute subdural hematoma after mild head injury with normal computed tomography: a case report and brief review. J Trauma 65:461463,2008

56. McAbee GN, Ciminera PF: Intracranial hematoma in experienced teenage equestrians. Pediatr Neurol 15:235-236, 1998

57. McCrory P: Does second impact syndrome exist? Clin J Sport Med 11:144-149, 2001

58. McCrory P, Davis G, Makdissi M: Second impact syndrome or cerebral swelling after sporting head injury. Curr Sports Med Rep 11:21-23, 2012

59. McCrory P, Meeuwisse W, Johnston K, Dvorak J, Aubry M, Molloy M, et al: Consensus Statement on Concussion in Sport: the 3rd International Conference on Concussion in Sport held in Zurich, November 2008. Br J Sports Med 43 (Suppl 1):i76i90, 2009

60. McCrory PR, Berkovic SF: Second impact syndrome. Neurology 50:677-683, 1998

61. McCrory PR, Berkovic SF, Cordner SM: Deaths due to brain injury among footballers in Victoria, 1968-1999. Med J Aust 172:217-219, 2000

62. Mohanty A, Kolluri VR, Subbakrishna DK, Satish S, Mouli BA, Das BS: Prognosis of extradural haematomas in children. Pediatr Neurosurg 23:57-63, 1995

63. Mori K, Yamamoto T, Horinaka N, Maeda M: Arachnoid cyst is a risk factor for chronic subdural hematoma in juveniles: twelve cases of chronic subdural hematoma associated with arachnoid cyst. J Neurotrauma 19:1017-1027, 2002

64. Mori T, Katayama Y, Kawamata T: Acute hemispheric swelling associated with thin subdural hematomas: pathophysiology of repetitive head injury in sports. Acta Neurochir Suppl 96:40-43, 2006

65. Mueller FO, Cantu RC: Annual Survey of Catastrophic Football Injuries. 1977-2011. (http://www.unc.edu/depts/ nccsi/FBCATReport2011.pdf) [Accessed October 16, 2012]

66. National Operating Committee on Standards for Athletic Equipment: NOCSAE Standard Performance Specification for Recertified Football Helmets. (http://www.nocsae. org/standards/pdfs/Standards\%20'12/ND004-11m12-\%20Re cert $\% 20 \mathrm{FB} \% 20 \mathrm{Helmets} \% 20$ Standard\%20Performance.pdf) [Accessed October 16, 2012]

67. Nemecek AN, Ellenbogen RG, Britz GW: Vertex epidural hematoma. Pediatr Neurosurg 41:170-172, 2005

68. NeuroPoint Alliance: The National Neurosurgery Quality and Outcomes Datbase ( $N^{2}$ QOD) Project Objectives and
Data Collection Guidelines V1.0. (http://www.neuropoint. $\mathrm{org} / \mathrm{pdf} / \mathrm{N} 2 \mathrm{QOD} \% 20$ data\%20management $\% 20$ and $\% 20$ Pro ject\%20Objectives\%20January\%202012\%20V\%201.0.pdf) [Accessed October 16, 2012]

69. Nishio M, Akagi K, Abekura M, Maeda Y, Matsumoto K: [A case of traumatic subacute subdural hematoma presenting symptoms arising from cerebral hemispheric edema.] No Shinkei Geka 26:425-429, 1998 (Jpn)

70. Noonan VK, Kwon BK, Soril L, Fehlings MG, Hurlbert RJ, Townson A, et al: The Rick Hansen Spinal Cord Injury Registry (RHSCIR): a national patient-registry. Spinal Cord 50: 22-27, 2012

71. Parsch CS, Krauss J, Hofmann E, Meixensberger J, Roosen K: Arachnoid cysts associated with subdural hematomas and hygromas: analysis of 16 cases, long-term follow-up, and review of the literature. Neurosurgery 40:483-490, 1997

72. Petraglia AL, Maroon JC, Bailes JE: From the field of play to the field of combat: a review of the pharmacological management of concussion. Neurosurgery 70:1520-1533, 2012

73. Potts MA, Stewart EW, Griesser MJ, Harris JD, Gelfius CD, Klamar K: Exceptional neurologic recovery in a teenage football player after second impact syndrome with a thin subdural hematoma. PM R 4:530-532, 2012

74. Powell JW, Barber-Foss KD: Traumatic brain injury in high school athletes. JAMA 282:958-963, 1999

75. Prabhu VC, Bailes JE: Chronic subdural hematoma complicating arachnoid cyst secondary to soccer-related head injury: case report. Neurosurgery 50:195-198, 2002

76. Rajan GP, Zellweger R: Half pipe snowboarding: an (un)forgettable experience or an increasing risk for head injury? Br J Sports Med 38:e35, 2004

77. Raschka VC, Roth J, Sitte T, Gödecke A, Haas JP, Hammar $\mathrm{CH}$ : [Fatal soccer injury as an unfortunate sequela of collision.] Sportverletz Sportschaden 9:24-26, 1995 (Ger)

78. Reddy CC, Collins M, Lovell M, Kontos AP: Efficacy of amantadine treatment on symptoms and neurocognitive performance among adolescents following sports-related concussion. J Head Trauma Rehabil [epub ahead of print], 2012

79. Report of the Quality Standards Subcommittee: Practice parameter: the management of concussion in sports (summary statement). Neurology 48:581-585, 1997

80. Rughani AI, Lin CT, Ares WJ, Cushing DA, Horgan MA, Tranmer BI, et al: Helmet use and reduction in skull fractures in skiers and snowboarders admitted to the hospital. Clinical article. J Neurosurg Pediatr 7:268-271, 2011

81. Sahjpaul RL, Abdulhak MM, Drake CG, Hammond RR: Fatal traumatic vertebral artery aneurysm rupture. Case report. J Neurosurg 89:822-824, 1998

82. Sarmiento K, Mitchko J, Klein C, Wong S: Evaluation of the Centers for Disease Control and Prevention's concussion initiative for high school coaches: "Heads Up: Concussion in High School Sports.” J Sch Health 80:112-118, 2010

83. Saunders RL, Harbaugh RE: The second impact in catastrophic contact-sports head trauma. JAMA 252:538-539, 1984

84. Sawyer RJ, Hamdallah M, White D, Pruzan M, Mitchko J, Huitric M: High school coaches' assessments, intentions to use, and use of a concussion prevention toolkit: Centers for Disease Control and Prevention's Heads Up: Concussion in High School Sports. Health Promot Pract 11:34-43, 2010

85. Schneider R: Head and Neck Injuries in Football: Mechanisms, Treatment, and Prevention. Baltimore: Williams \& Wilkins, 1973

86. Schwartz MF, Brecher AR, Whyte J, Klein MG: A patient registry for cognitive rehabilitation research: a strategy for balancing patients' privacy rights with researchers' need for access. Arch Phys Med Rehabil 86:1807-1814, 2005

87. Sener RN: Arachnoid cysts associated with post-traumatic and spontaneous rupture into the subdural space. Comput Med Imaging Graph 21:341-344, 1997 


\section{S. L. Zuckerman et al.}

88. Shahlaie K, Keachie K, Hutchins IM, Rudisill N, Madden LK, Smith KA, et al: Risk factors for posttraumatic vasospasm. Clinical article. J Neurosurg 115:602-611, 2011

89. Snoek JW, Minderhoud JM, Wilmink JT: Delayed deterioration following mild head injury in children. Brain 107:15-36, 1984

90. Solomon GS, Sills AK: Pharmacologic treatment of sport-related concussion: a review. J Surg Orthop Adv [in press], 2012

91. Strebel S, Lam AM, Matta BF, Newell DW: Impaired cerebral autoregulation after mild brain injury. Surg Neurol 47:128131,1997

92. Sullivan SJ, Schneiders AG, Cheang CW, Kitto E, Lee H, Redhead J, et al: 'What's happening?' A content analysis of concussion-related traffic on Twitter. Br J Sports Med 46:258-263, 2012

93. Thomas M, Haas TS, Doerer JJ, Hodges JS, Aicher BO, Garberich RF, et al: Epidemiology of sudden death in young, competitive athletes due to blunt trauma. Pediatrics 128:e1-e8, 2011

94. Tsuzuki N, Katoh H, Ohtani N: Chronic subdural hematoma complicating arachnoid cyst secondary to soccer-related head injury: case report. Neurosurgery 53:242-243, 2003 (Letter)

95. Türkoğlu E, Serbes G, Sanli M, Sari O, Sekerci Z: Chronic subdural hematoma in capoeira sport. Turk Neurosurg 18: 39-41, 2008

96. Uzura M, Taguchi Y, Matsuzawa M, Watanabe H, Chiba S: Chronic subdural haematoma after snowboard head injury. Br J Sports Med 37:82-83, 2003

97. Vassilyadi M, Duquette C, Shamji MF, Orders S, Dagenais S: Evaluation of ThinkFirst for kids injury prevention curriculum for grades 7/8. Can J Neurol Sci 36:761-768, 2009

98. Vigil DV, DiFiori JP, Puffer JC, Peacock WJ: Arachnoid cyst and subdural hygroma in a high school football player. Clin J Sport Med 8:234-237, 1998
99. Wang A, Cohen AR, Robinson S: The "swing-ding": a golfrelated head injury in children. Clinical article. J Neurosurg Pediatr 7:111-115, 2011

100. Wester K: Peculiarities of intracranial arachnoid cysts: location, sidedness, and sex distribution in 126 consecutive patients. Neurosurgery 45:775-779, 1999

101. Wetjen NM, Pichelmann MA, Atkinson JL: Second impact syndrome: concussion and second injury brain complications. J Am Coll Surg 211:553-557, 2010

102. Yang SN, Park SW, Jung HY, Rah UW, Kim YH, Chun MH, et al: Korean Brain Rehabilitation Registry for rehabilitation of persons with brain disorders: annual report in 2009. J Korean Med Sci 27:691-696, 2012

103. Zeng T, Shi SS, Lin YF: Chronic subdural hematoma associated with sylvian arachnoid cyst in juvenile athletes: report of two cases and literature review. Chin J Traumatol 14: 174-177, 2011

104. Zhang H, Zhang JM, Chen G: Chronic subdural hematoma associated with arachnoid cyst: report of two cases. Chin Med J (Engl) 120:2339-2340, 2007

105. Zuckerman SL, Odom MJ, Lee YM, Forbes J, Sills AK, Solomon GS: 145 Sport-related concussion and age: number of days to neurocognitive baseline. Surg Neurol Int [in press], 2012

Manuscript submitted August 15, 2012.

Accepted October 4, 2012.

Please include this information when citing this paper: DOI: 10.3171/2012.10.FOCUS12279.

Address correspondence to: Scott L. Zuckerman, M.D., Department of Neurological Surgery, Vanderbilt Medical Center, T-4224 Medical Center North, Nashville, Tennessee 37232-2380. email: scott.zuckerman@vanderbilt.edu. 